\title{
A cohort study of maternal and fetal outcomes for myomectomy at caesarean section in Aba, South Eastern Nigeria
}

\author{
Chisara C. Umezurike ${ }^{1 *}$, Emmanuel M. Akwuruoha², Kelechi N. Eguzo ${ }^{1,3}$ \\ ${ }^{1}$ Department of Obstetrics \& Gynaecology, Nigerian Christian Hospital, Aba, Nigeria \\ ${ }^{2}$ Department of Obstetrics \& Gynaecology, Abia State University Teaching Hospital, Aba, Nigeria \\ ${ }^{3}$ School of Public Health, University of Saskatchewan, Saskatoon, Canada
}

Received: 28 August 2014

Accepted: 19 September 2014

*Correspondence:

Dr. Chisara C. Umezurike,

E-mail: umeztochi@hotmail.com

Copyright: (C) the author(s), publisher and licensee Medip Academy. This is an open-access article distributed under the terms of the Creative Commons Attribution Non-Commercial License, which permits unrestricted non-commercial use, distribution, and reproduction in any medium, provided the original work is properly cited.

\begin{abstract}
Background: Fibroids in pregnancy are common in Nigeria but myomectomy during caesarean section is not popular due to concerns for severe hemorrhage. Previous studies did not directly compare outcome for routine Caesarean Section (CS) with Caesarean Myomectomy (CM). This prospective cohort study compares the maternal and fetal outcomes of caesarean myomectomy (exposed arm) with caesarean section (control arm); $(\mathrm{n}=64 ; \mathrm{CM}=34 ; \mathrm{CS}=30)$. Methods: Variables include maternal age, durations of surgery and hospitalization, Estimated Blood Loss (EBL), as well as pre and postoperative hematocrit. Fetal weight, number and weight of fibroids were also considered. Data was analyzed with SPSS using descriptive statistics and chi-square tests.

Results: There was no significant difference in EBL, incidence of postoperative complications, fetal APGAR score at 5 minutes as well as duration of hospitalization between both groups. Number of fibroids ( $>10)$ was significantly associated with blood transfusion $\left(X^{2}=11.46, \mathrm{P}<0.001\right)$, and was found to be strongly correlated with longer duration of surgery ( $\mathrm{r}=0.79 ; \mathrm{P}<0.001)$.

Conclusions: Study suggests that caesarean myomectomy maybe a safe procedure, with good maternal and fetal outcomes, in well-selected patients, especially those with $<10$ fibroids in pregnancy. Caution should be applied in patients with $>10$ fibroids. We recommend use of total number of fibroids as an index of surgical risk, instead of dimension of fibroids, as correlates significantly with duration of surgery and estimated blood loss.
\end{abstract}

Keywords: Caesarean section, Caesarean myomectomy, Fibroid in pregnancy, Cohort study, Maternal outcome

\section{INTRODUCTION}

Uterine fibroid is the commonest tumor in women affecting up to $75 \%$ of women of reproductive age. ${ }^{1}$ Evidence suggests that more than $60 \%$ of non-gravid African-American women and about $40 \%$ of non-gravid Caucasian women have leiomyomas identifiable by ultrasound by 35 years of age. ${ }^{2}$ The prevalence of uterine leiomyoma in pregnancy varies between 1.6 and 10.7 percent depending upon the trimester of assessment and the size threshold. ${ }^{1,3}$
During pregnancy, uterine fibroid are usually asymptomatic but may be occasionally complicated by red degeneration and an increased frequency of spontaneous abortion, preterm labour, premature rupture of fetal membranes, ante partum hemorrhage, malpresentations, obstructed labour, caesarean section and postpartum hemorrhage. ${ }^{1,3-5}$

The management of uterine fibroid in pregnancy is largely expectant and its surgical removal is generally delayed until after delivery. $3,4,6$ 
Myomectomy during caesarean section is usually avoided by most obstetricians because of increased risk of uncontrollable hemorrhage from the highly vascularized pregnant uterus. ${ }^{1,7-9}$ Caesarean myomectomy was therefore unknown in the obstetric literature until the last two decades, although recent reports show that myomectomy at cesarean section may be safe in selected cases. ${ }^{1,10}$ Some West African researchers have compared the outcome of myomectomy at caesarean section with those women who had caesarean section alone through case series and case control studies. ${ }^{1,5}$ These considered the sites and numbers of fibroids, and not the cumulative weight of the tumors-which could be another index of tumor burden. No African study has shown the correlation between maternal BMI and pregnancy outcome for women undergoing caesarean myomectomy, and there is no literature which shows fetal outcome for women undergoing this procedure.

This study therefore seeks to compare the maternal and fetal outcome for patients undergoing Caesarean Myomectomy (CM) with those who underwent caesarean section for fibroid in pregnancy.

\section{METHODS}

\section{Study design and patient selection}

This study was designed as a prospective cohort study of a select group of pregnant patients having uterine fibroid but undergoing caesarean with myomectomy, caesareanmyomectomy (CM; exposed arm) compared with similar patients who had only caesarean section (CS; nonexposed arm) without myomectomy. Study was conducted in Nigerian Christian hospital, Aba between March 2004 and March 2010, following approval from the department of obstetrics and gynaecology.

Patients included in this study had ultrasound-confirmed uterine fibroid in index pregnancy, without evidence of antepartum hemorrhage. They had no comorbid conditions, such as coagulopathy. Selected patients had symptomatic fibroid, with pain of worsening severity during the pregnancy. A convenience sample of patients who consented to this procedure was used for the study. Informed, written, consent was obtained from patients who met the inclusion criteria, after they were counseled on the risks and benefits of CM and CS. Patients included in this study were followed from their second antenatal visit till their discharge following surgery. Post-natal visit was conducted at the $6^{\text {th }}$ week post-partum. This was to ensure adequate monitoring of blood counts, preoperative conditions as well as postoperative outcomes.

A total of sixty-four patients $(n=64)$ were recruited into the study. Thirty-four (34) patients with uterine fibroids in pregnancy benefited from caesarean myomectomy (CM), while 30 patients who also had uterine fibroids in pregnancy but declined CM or in whom uterine fibroids were incidental findings were selected only benefited from routine Caesarean Section (CS). These formed the exposed and unexposed arms of this study, respectively. Table 1 shows the baseline characteristics of our study population.

\section{Variables}

Parameters considered were age; parity; and gestational age at delivery. Other criteria were Body Mass Index (BMI) at diagnosis, preoperative hematocrit, postoperative hematocrit, estimated intraoperative blood loss, units of blood transfused, postoperative complications, duration of hospital stay (days), operative time (minutes), number of fibroids removed, weights of fibroids removed $(\mathrm{kg})$ and sites/locations of fibroids removed. We also considered fetal outcome such as birth weight as well as APGAR scores at 1 and 5 minutes, respectively. A reduction in hematocrit greater 10 points from the preoperative values or the need for intraoperative transfusion were classified as hemorrhage, while anemia was defined as postoperative hematocrit below 30\%. Operative time (minutes) was calculated from skin incision to skin closure. We defined postoperative fever as axillary temperature greater than or equal to $38.0^{\circ}$ centigrade.

\section{Surgical procedure}

After anesthesia, routine cleaning and draping, the abdomen was entered either by Joel Cohen's or midline incision. The choice of incision was influenced by preoperative estimation of fibroid size and preexisting abdominal incisions. The fetus was delivered via transverse lower uterine segment caesarean section, followed by delivery of the placenta and closure of the transverse lower segment incision.

Next, Foleys catheter was applied circumferentially around the lower uterine segment avoiding the fallopian tubes and the ovaries, to act as a tourniquet. Routine myomectomy was then carried out and myoma beds were closed in layers. The serosa layer was closed with continuous number 2-0 polydioxanone suture. The Foley's catheter was removed and incision areas were inspected for bleeding while oxytocin infusion was commenced and continued for twenty-four hours. The abdomen was closed in layers.

\section{Statistical analysis}

Data collected for this study did not meet the assumption of normality using the Shapiro-Wilk test for normality ( $P$ $<0.001)$, thus non-parametric methods were used for data analysis. Chi-square and Fisher exact tests were used to compare differences between the 2 study groups (Cmyomectomy and C-section). Patient's age was grouped as below 25; 26-34 years and above 35 years, in line with previously published literature..$^{5}$ There was no published classification of fibroids based on weight, so we arbitrarily classified them based on fetal weight, as $<1.5$ 
$\mathrm{kg}$; $1.5-2.4 \mathrm{~kg} ; 2.5-3.9 \mathrm{~kg}$; and $\geq 4 \mathrm{~kg}$ respectively. We defined good maternal outcome as hospitalization not greater than 7 days, post-operative hematocrit greater than $30 \%$ with no post-operative complication and not having post-partum hemorrhage (EBL $\leq 1000 \mathrm{ml}$ ). Each of these indices were compared between the 2 groups to determine any statistically significant differences, at $\alpha=0.05$.

\section{RESULTS}

A total of 64 patients were involved in this study; 34 had caesarean myomectomy (exposed) and 30 had caesarean section (unexposed). Table 1 summarizes the baseline characteristics of the study population. There was no correlation between age of patient with number and weight of fibroids, $\mathrm{P}=0.82$ and 0.27 respectively. No association was found between weight of fibroid and Apgar score at 5 minutes $(\mathrm{P}=0.90)$. A moderate positive correlation was found between weight of fibroid and number of fibroids $(\mathrm{r}=0.5 ; \mathrm{P}=0.02)$. The weight of fibroid was not significantly associated with fetal birth weight $(\mathrm{P}=0.90)$. There was no statistically significant difference in duration of hospitalization based on surgery type $(\mathrm{P}=0.71)$.

Table 2 summarizes the outcomes between the two groups.

Table 1: Baseline characteristics of study population.

\begin{tabular}{|c|c|c|c|}
\hline Parameter & Description & $\begin{array}{l}\text { Caesarean } \\
\text { myomectomy } \\
(\%) \mathrm{n}=\mathbf{3 4}\end{array}$ & $\begin{array}{l}\text { Caesarean } \\
\text { section } \\
(\%) n=30\end{array}$ \\
\hline \multirow{2}{*}{$\begin{array}{l}\text { Booking } \\
\text { status }\end{array}$} & Unbooked & $4(6.2)$ & $11(17.2)$ \\
\hline & Booked & $30(46.9)$ & $19(29.7)$ \\
\hline \multirow{3}{*}{ Parity } & Nullipara & $28(43.8)$ & $18(28.1)$ \\
\hline & Multipara & $6(9.4)$ & $9(14.1)$ \\
\hline & $\begin{array}{l}\text { Grand } \\
\text { multipara }\end{array}$ & $0(0)$ & $3(4.7)$ \\
\hline Age (years) & Mean \pm SD & $32.7 \pm 3.7$ & $31.0 \pm 5.7$ \\
\hline \multirow{3}{*}{$\begin{array}{l}\text { Maternal } \\
\text { age group }\end{array}$} & $\begin{array}{l}\text { Below } 25 \\
\text { years }\end{array}$ & $1(1.6)$ & $5(7.8)$ \\
\hline & 26-34 years & $21(32.8)$ & $18(28.1)$ \\
\hline & $\geq 35$ years & $12(18.8)$ & $7(10.9)$ \\
\hline \multirow{2}{*}{$\begin{array}{l}\text { Gestational } \\
\text { age }\end{array}$} & Preterm & $2(3.1)$ & $1(1.6)$ \\
\hline & Term & $32(50.0)$ & $29(45.3)$ \\
\hline \multirow{4}{*}{$\begin{array}{l}\text { Body mass } \\
\text { index }\end{array}$} & Underweight & $0(0)$ & $2(3.2)$ \\
\hline & Normal & $16(25.4)$ & $6(9.5)$ \\
\hline & Overweight & $13(20.6)$ & $13(20.6)$ \\
\hline & Obese & $4(6.3)$ & $9(14.3)$ \\
\hline $\begin{array}{l}\text { Gestational } \\
\text { age }\end{array}$ & Mean \pm SD & $38.6 \pm 1.6$ & $39.2 \pm 1.6$ \\
\hline $\begin{array}{l}\text { Preoperative } \\
\text { PCV }\end{array}$ & Mean \pm SD & $33.6 \pm 5.0$ & $35.6 \pm 4.0$ \\
\hline
\end{tabular}

Table 2: Summary of outcomes of for caesarean myomectomy and caesarean section patients.

\begin{tabular}{|c|c|c|c|}
\hline Parameter & $\begin{array}{l}\text { Caesarean } \\
\text { myomecto- } \\
\text { my }(n=34)\end{array}$ & $\begin{array}{l}\text { Caesarean } \\
\text { section } \\
(n=30)\end{array}$ & $\begin{array}{l}\text { P value } \\
(\alpha=0.05)\end{array}$ \\
\hline $\begin{array}{l}\text { Proportion without } \\
\text { PPH* } \\
(\text { EBL <1000 ml) }\end{array}$ & $82.4 \%$ & $90 \%$ & \multirow{2}{*}{0.49} \\
\hline $\begin{array}{l}\text { Proportion with } \\
\text { PPH* }^{*} \\
(\text { EBL }>1000 \mathrm{ml})\end{array}$ & $17.6 \%$ & $10 \%$ & \\
\hline $\begin{array}{l}\text { proportion with } \\
\text { significant post-op } \\
\text { anemia }(\mathrm{PCV}<30)\end{array}$ & $79.4 \%$ & $46 \%$ & $0.009 * *$ \\
\hline $\begin{array}{l}\text { Proportion with } \\
\text { good clinical } \\
\text { outcome } \\
\text { (no complication) }\end{array}$ & $70.6 \%$ & $76.7 \%$ & \multirow{2}{*}{0.78} \\
\hline $\begin{array}{l}\text { Proportion with } \\
\text { poorer clinical } \\
\text { outcome } \\
\text { ( } \geq 1 \text { complication) }\end{array}$ & $29.4 \%$ & $23.3 \%$ & \\
\hline $\begin{array}{l}\text { Hospitalization } \\
<7 \text { days }\end{array}$ & $85.3 \%$ & $90 \%$ & \multirow{2}{*}{0.71} \\
\hline $\begin{array}{l}\text { Hospitalization } \\
>7 \text { days }\end{array}$ & $14.7 \%$ & $10 \%$ & \\
\hline $\begin{array}{l}\text { Low APGAR } \\
\text { score }\end{array}$ & $2.9 \%$ & $10 \%$ & \multirow{2}{*}{0.33} \\
\hline $\begin{array}{l}\text { Normal APGAR } \\
\text { score }\end{array}$ & $97.1 \%$ & $90 \%$ & \\
\hline $\begin{array}{l}\text { Duration of } \\
\text { surgery (minutes) } \\
\text { Mean } \pm \mathrm{SD}\end{array}$ & $113.6 \pm 41$ & $40.3 \pm 13.1$ & $<0.001 * *$ \\
\hline $\begin{array}{l}\text { Proportion } \\
\text { requiring } \geq 1 \text { unit } \\
\text { of blood }\end{array}$ & $44.1 \%$ & $13.3 \%$ & $0.013^{* *}$ \\
\hline
\end{tabular}

*PPH: post-partum hemorrhage; **statistically significant differences

There was no significant difference between both groups in terms of good surgical outcome (defined as absence of postoperative complications). Figure 1 shows the distribution of complications by types of surgery. There was no significant difference in surgical outcome by patients' age or parity. However, among patients who underwent $\mathrm{CM}, 50 \%$ of the cases with complications were aged 26-24 years $(\mathrm{P}=0.25)$. No statistically significant association was found between complications and patients' parity among, especially among those who underwent CM. The weight of the fibroid was not a significant predictor of clinical outcome $(P=0.89)$. There was no significant association between patients' BMI and good surgical outcome in the CM group $(\mathrm{P}=0.43)$. Surgical outcome was not significantly associated with gestational age $(\mathrm{P}=1.0 \mathrm{CM}, 0.23 \mathrm{CS})$ nor with fetal birth weight $(\mathrm{P}=0.76 \mathrm{CM}, 0.57 \mathrm{CS})$. 


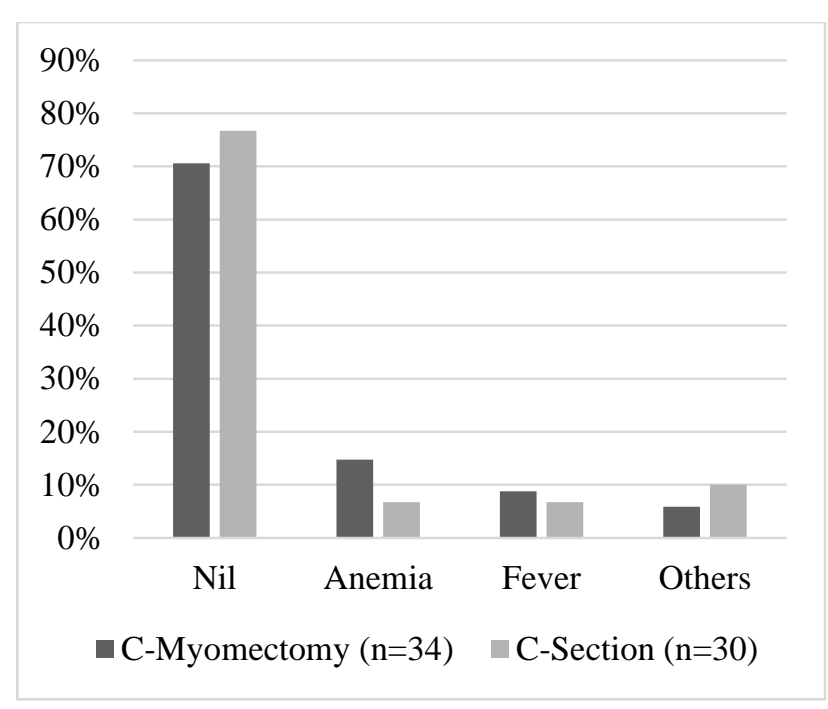

Figure 1: Distribution of postoperative complications, caesarean myomectomy, NCH 2004-10.

There was a moderate positive correlation between duration of surgery and volume of blood loss $(\mathrm{r}=0.5 ; \mathrm{P}=$ $0.006)$ There was no statistically significant difference in the duration of hospital stay and post-operative fever between the CM and CS groups. There was one case of relaparotomy and peripartum hysterectomy due to uterine atony in the CM group. Other complications reported among the patients were spinal headache $(10.0 \%)$ and adynamic ileus $(10.0 \%)$ among the CM group, while UTI $(14.3 \%)$ and wound dehiscence $(14.3 \%)$ were diagnosed among the CS group.

Most of the myomas were at multiple sites. All the patients for caesarean myomectomy had subserosal myomas, while $76 \%$ of them had intramural fibroids (Table 3). There was a significant association between number of myomas and blood transfusion; patients with $>10$ myoma were more likely to be transfused $\left(X^{2}=11.46\right.$, $\mathrm{P}<0.001)$.

Table 3: Description of myomas in CM cases.

\begin{tabular}{|c|c|c|}
\hline Parameter & Description & Number (\%) \\
\hline \multirow{3}{*}{ Site of myomas } & Subserosal* & $34(100.0)$ \\
\hline & Intramural & $26(76.4)$ \\
\hline & Submucosal & $7(20.5)$ \\
\hline \multirow{4}{*}{$\begin{array}{l}\text { Weight of myomas } \\
\text { / patient }(\mathrm{kg})\end{array}$} & $<1.5$ & $24(70.6)$ \\
\hline & $1.5-2.4$ & $4(11.8)$ \\
\hline & $2.5-3.9$ & $3(8.8)$ \\
\hline & $\geq 4.0$ & $3(8.8)$ \\
\hline \multirow{3}{*}{$\begin{array}{l}\text { Number of myomas } \\
\text { / patient }\end{array}$} & $<10$ & $18(52.9)$ \\
\hline & $10-19$ & $6(17.6)$ \\
\hline & $\geq 20$ & $10(29.4)$ \\
\hline $\begin{array}{l}\text { Average number of } \\
\text { myomas } \pm \text { SD }\end{array}$ & & $14 \pm 11$ \\
\hline
\end{tabular}

*All cases had myomas in multiple sites, including subserosal

\section{DISCUSSION}

Uterine fibroid is a very common benign tumor in women of African descent. There has been an increasing incidence of pregnancies complicated by uterine fibroids in recent years, especially as women delay child bearing for various reasons. It is not uncommon therefore to encounter uterine fibroids during caesarean sections in our environment. ${ }^{5,6,11}$

Traditionally, caesarean myomectomy has been discouraged in obstetrics because of risks of intractable hemorrhage and increased post-operative morbidity. ${ }^{7,10,12,13}$

Our study however, found out that the risk of significant hemorrhage $(\mathrm{EBL}>1000 \mathrm{ml}$ ) was not different between patients who underwent $\mathrm{CM}$ or $\mathrm{CS}(\mathrm{P}=0.49)$. In an attempt at risk stratification, we found no significant correlation between the numbers of fibroids, patient's BMI, parity and estimated blood loss, respectively. Other studies from West Africa ${ }^{1,5,10}$ did not demonstrate significantly higher blood loss for caesarean myomectomy cases; but these did not examine the impact of the number and weight of fibroids on EBL and maternal outcome. However, CM patients had significantly lower postoperative hematocrit compared with CS cases $(\mathrm{P}=0.009)$.

Furthermore, we compared differences in surgical outcome for patients undergoing CM and CS. Good surgical outcome was described as absence of complications post-surgery. We found no significant difference in the proportion of patients with poorer outcome $(\geq 1$ complication) in both groups $(P=0.78)$. This goes to support the argument that caesarean myomectomy is a safe procedure in well-selected patients. $^{4,5,11}$

In our context, these are patients without preoperative anemia having $<10$ myomas. One patient in the CM group had re-laparotomy and caesarean hysterectomy due to uncontrollable post-partum hemorrhage from uterine atony; this patient had multiple fibroids greater than 10 in number and weighing greater than $500 \mathrm{~g}$. Figure 1 shows the distribution of postoperative complications in the study population. Moreover it has been suggested that injury to the uterus may be less traumatic when myomectomy is performed during caesarean section compared to outside pregnancy as the relative size of myoma to the uterus is smaller during pregnancy compared to non-pregnancy. ${ }^{9}$

We also compared fetal outcome for patients with fibroid in pregnancy. There was no significant association between number of fibroids and fetal weight $(P=0.90)$. Apgar score in 5 minutes was not associated with weight 
of fibroids $(\mathrm{P}=0.90)$. Apgar in 5 minutes has been shown to be a valid predictor of neonatal outcome. ${ }^{15}$ No previously published work from our review estimated the impact of fibroids in pregnancy on fetal outcome. But our findings maybe inconclusive due to small sample size $(n=34)$. Fibroid in pregnancy did not appear to impact gestational age in both arms of the study. Mean gestational age in CM group was $38.6 \pm 1.6$ ) weeks while the CS group had $39.2 \pm 1.6$ weeks. It could however, be argued that most of these cases were elective surgeries, so their gestational age was predetermined. Our practice is to carry out caesarean myomectomy after 38 completed weeks, to ensure good fetal maturity and viability.

All the patients in the CM group had multiple fibroids, often involving the serosa. Intramural fibroids were more common than submucosal fibroids $(76 \%$ vs. $21 \%)$. This is similar to the trend reported in literature. ${ }^{1,5,9}$

Our study is the first to describe the outcome for caesarean myomectomy in terms of total number and weight of fibroids, instead of dimension of fibroids as used by other researchers. ${ }^{11}$

We argue that weight and number of fibroids are better predictors of disease burden than dimension of fibroids, as they impact duration of surgery. There was a strong positive correlation between number of fibroids and duration of surgery $(\mathrm{r}=0.79, \mathrm{P}<0.001)$. Longer surgeries were also found to be associated with significant hemorrhage in both groups $(\mathrm{P}<0.001)$.

Kim et al. ${ }^{14}$ reported increased risk of complications in caesarean myomectomy patients with fibroids greater than $10 \mathrm{~cm}$ and those with intramural myoma. We suggest that grouping the weight of fibroids relative to the standard classification of fetal weight would put the relative impact of fibroids on the fetus in clearer context. Further research is recommended to explore test this hypothesis.

Finally, we attempted to risk-stratify $\mathrm{CM}$ patients in terms of body mass index, age, parity and number of fibroids. Number of fibroids was the only significant predictor of clinical outcome. Patients with $>10$ fibroids or fibroids weighing $>500 \mathrm{~g}$ were significantly more likely to be transfused $\left(X^{2}=11.46, \mathrm{P}<0.001\right)$, and were more likely to have poorer surgical outcome ( $\geq 1$ postoperative complication).

Although other studies ${ }^{1,7,14}$ have advised against carrying out caesarean myomectomy in patients with multiple fibroids, fundal intramural fibroids in the vicinity of the tubes, and patients with dense pelvic adhesions; we would clarify that the danger in multiple fibroid is significant if there are $>10$ fibroids. We also avoided caesarean myomectomy in patients with big broad ligament fibroids. The impact of this study however, maybe limited by our small sample size $(n=64)$. Further research with larger sample size could help explore our findings.

\section{CONCLUSIONS}

We found no difference in good clinical outcome between patients undergoing Caesarean Myomectomy (CM) with those undergoing Caesarean Section (CS).

Total number and weight of fibroids have been advocated as indices of the burden of fibroids (instead of dimensions of lesions) as they impact operative time and blood loss significantly.

Caesarean myomectomy should be carried out with caution and with adequate cross-matched blood for patients with multiple fibroids greater than 10 .

Funding: No funding sources

Conflict of interest: None declared

Ethical approval: The study was approved by the institutional ethics committee

\section{REFERENCES}

1. Kwawukume EY. Myomectomy during cesarean section. Int J Gynaecol Obstet. 2002;76(2):183-4.

2. Baird DD, Hill MC, Cousins D, Schectman JM. High cumulative incidence of uterine leiomyoma in black and white women: ultrasound evidence. Am J Obstet Gynaecol. 2003;188(1):100-7.

3. Kaymak O, Ustunyurt E, Okyay RE, Kalyoncu S, Mollamahmutoglu L. Myomectomy during cesarean section. Int J Gynaecol Obstet. 2005;89(2):90-3.

4. Umezurike C, Waboso FP. Successful myomectomy during pregnancy: a case report. Reprod Health. 2005;2:6.

5. Ehigiegba AE, Ande AB, Ojobo SI. Myomectomy during cesarean section. Int $\mathrm{J}$ Gynaecol Obstet. 2001;75(1):21-5.

6. Lee HJ, Norwits ER, Shaw J. Contemporary management of uterine fibroids in pregnancy. Rev Obstet Gynaecol. 2010;3(1):20-7.

7. Roman AS, Tabsh KMA. Myomectomy at time of caesarean delivery: a retrospective cohort study. BMC Pregnancy Childbirth. 2004;4(1):14.

8. Park BJ, Kim KY. Safety of caesarean myomectomy. J Obstet Gynaecol Res. 2009;35:906-11.

9. Lin H, Juan D, Jin L, Shi Z, Lui M. Myomectomy during caesarean section. Acta Obstet Gynaecol. 2009;88(2):183-6.

10. Umezurike CC. Caesarean myomectomy in Aba, Southeastern Nigeria. Trop Doctor. 2007;37:109-11.

11. Song D, Zhang W, Chames MC, Guo J. Myomectomy during cesarean delivery. Int $\mathbf{J}$ Gynaecol Obstet. 2013;121(3):208-13.

12. Ikedife D. Surgical challenge of myomectomy at caesarean section. Niger J Surg Sci. 1993;3:15-7.

13. Cobellis L, Peroci E, Cobellis G. Hemostatic technique for myomectomy during caesarean section. Int J Gynaecol Obstet. 2002;79:261-2. 
14. Kim YS, Choi SD, Bas DH. Risk factors for complications in patients undergoing myomectomy at the time of caesarean section. J Obstet Gynaecol Res. 2010;36(3):550-5.

15. ACOG Committee Opinion No. 333. American College of Obstetricians and Gynecologists. The APGAR score. Obstet Gynaecol. 2006;107:1209-12.
DOI: $10.5455 / 2320-1770 . i j r \operatorname{cog} 20141212$

Cite this article as: Umezurike $\mathrm{CC}$, Akwuruoha

EM, Eguzo KN. A cohort study of maternal and fetal outcomes for myomectomy at caesarean section in Aba, South Eastern Nigeria. Int J Reprod Contracept Obstet Gynecol 2014;3:936-41. 